\title{
Further Considerations on the Need of a Specific BCG Vaccination Programme for Foreign New-borns
}

Irene Bellini ${ }^{{ }^{*}}$, Antonino Nastasi ${ }^{2}$ and Sara Boccalini ${ }^{2}$

${ }^{1}$ Specialization Medical School of Hygiene and Preventive Medicine, University of Florence, Florence, Italy

${ }^{2}$ Department of Health Sciences, University of Florence, Florence, Italy

"Corresponding author: Irene Bellini, Specialization Medical School of Hygiene and Preventive Medicine, University of Florence, Florence, Italy, Tel: +358 2941 26643; E-mail: irenebellini86.ib@gmail.com

Received date: November 14, 2016; Accepted date: December 02, 2016; Published date: December 06, 2016

Copyright: (c) 2016 Bellini I, et al. This is an open-access article distributed under the terms of the Creative Commons Attribution License, which permits unrestricted use, distribution, and reproduction in any medium, provided the original author and source are credited.

\author{
Abstract \\ Background: A specific vaccination programme for foreign new-borns with BCG, implemented in Prato (Tuscany, \\ Italy), showed a reduction of TB specific hospitalisations.
}

A further analysis was conducted to investigate the TB hospitalisation rate specific for nationality in Tuscany.

Methods: A database containing all TB related hospitalisations in Tuscany during 2007-2014 was considered and stratified for year and for nationality. The annual number of foreign inhabitants for each nationality living in Tuscany was available online. The annual hospitalisation ratio/100,000 specific for nationality was then calculated and compared with WHO incidence rate of each native country.

Results: Average hospitalisation rate for the whole period was higher among immigrants from Albania, India, Senegal, Brazil and Russian federation and living in Tuscany than the average TB incidence rate of the native country. Instead among immigrants coming from Peru, Bangladesh and Philippines, it was lower. It was always higher in each foreign nationality than the overall incidence in Tuscany.

Discussion and conclusion: Unhealthy living and working conditions among some immigrants in Tuscany could increase the probability to become symptomatic from a condition of latent disease acquired in native countries. Besides overcrowding could facilitate transmission. In other cases rates are equal or lower than in the native countries but still higher than those of Tuscany population. Therefore, the enlargement of the BCG vaccination coverage for foreigners on the whole regional area could be now an actual and urgent issue in order to prevent new cases of TB.

\section{Background}

Prato, one of the major cities in Tuscany, central Italy, has the highest percentage of foreigners in the Region among its inhabitants (15.8\% in 2014) [1]. Here, the average annual notification rate of tuberculosis (TB) cases in the period 2007-2014 was higher compared to the other areas in Tuscany and Italy. Consequently, since 2000, Bacillus Calmette-Guérin (BCG) vaccine has been offered in Prato for all newborns with at least one foreign parent whose native country was TB-endemic.

The main object of our previous study [2] was assessing the impact of BCG vaccination offered to foreign children in Prato in terms of TBrelated hospitalization rate and costs during 2007-2014, compared to children living in the other areas in Tuscany, where the BCG vaccine has been not offered.

The conclusion of the study was that BCG immunization programme for foreign children in Prato was proved to reduce TB impact, in clinical and economical terms. Particularly, the risk of hospitalisation among unvaccinated foreign children living in the other areas of Tuscany resulted double compared with the risk in vaccinated ones living in Prato.
The object of the present article is a further analysis considering TB hospitalisation rate specific for nationality in Tuscany compared to TB incidence rate of each native country for the period 2007-2014.

\section{Methods}

The same database used to analyse the hospitalisations in the period 2007-2014, containing all the TB related hospitalisations occurred in the regional area during 2007-2014 (selected through ICD9 CM codes 010-018) and other details (city of living, age, gender, nationality, length of stay, diagnosis and costs) [2], was considered again to calculate the annual TB hospitalisation rate by nationality in Tuscany. It was calculated approximately as the ratio between the numbers of hospitalisations of patients with the selected nationality on the number of inhabitants of that nationality living in Tuscany (as registered by the Italian Institute of Statistic) [3] per 100,000 persons. Hospitalisation rate was considered the best approximation of incidence. Indeed, in the previous study TB notifications database was analysed too, but an important under-reporting was found: the number of notifications was unexpectedly lower than the number of hospitalisation having ICD9 codes specific for TB. Average hospitalisation rate for the whole period for each nationality was compared with average TB incidence rate of the native country during the same years, as reported by WHO in the 
TB report [4]. Analyses were conducted comparing incidence rates through CI 95\%: a difference was significant when selected CI 95\% did not overlap.

\section{Results}

Results are reported in Table 1 for the 12 most represented countries of origin, considering Confidence interval at 95\% (CI 95\%) of the incidences in Tuscany and according to WHO reports for the whole period 2007-2014.

\begin{tabular}{|l|l|l|}
\hline $\begin{array}{l}\text { Incidence/hospitalisation } \\
\text { per } \mathbf{1 0 0 , 0 0 0}\end{array}$ & Tuscany & WHO \\
\hline Romania & $110.0(79.0-140.9)$ & $105.4(93.1-117.7)$ \\
\hline Morocco & $123.5(92.5-154.5)$ & $101.4(99.5-103.2)$ \\
\hline China & $82.1(73.5-90.7)$ & $76.6(72.3-81.0)$ \\
\hline Albania & $22.9(18.0-27.7)$ & $17.3(16.6-17.9)$ \\
\hline Peru & $29.9(19.0-40.07)$ & $131(125.5-136.5)$ \\
\hline India & $240.6(199.0-282.3)$ & $183.4(175.0-191.7)$ \\
\hline Senegal & $272.2(161.6-382.7)$ & $136.6(136.0-137.3)$ \\
\hline Pakistan & $350.9(239.8-462.0)$ & $275.1(273.7-276.6)$ \\
\hline Bangladesh & $94.2(46.9-141.5)$ & $224.9(224.6-225.1)$ \\
\hline Brazil & $138.1(72.3-203.9)$ & $46.4(45.1-47.7)$ \\
\hline Russian Federation & $404.7(260.7-548.8)$ & $103.4(93.1-113.7)$ \\
\hline Philippines & $120.9(105.3-136.5)$ & $305.8(296.6-314.9)$ \\
\hline & & \\
\hline
\end{tabular}

Table 1: Annual incidence rate among foreigners living in Tuscany and the equivalent incidence rate according to WHO report (per 100,000).

As inferable from the table, hospitalisation rate, specific for nationality, was higher among Tuscany immigrants coming from Albania, India, Senegal, Brazil and Russian federation. Considering CI $95 \%$, hospitalisation is in all cases statistically different and higher compared to WHO incidence rate (cells are light grey).

Peru, Bangladesh and Philippines show instead lower values among immigrants that in the native countries (cells are dark grey). Other nationalities do not show significant differences (CI 95\% overlap).

\section{Discussion}

It seems that foreigners coming from Albania, India, Senegal, Brazil and Russian federation, and living in Tuscany fell ill more often than in their country. The explanation could lay in the known and already described effect of "exhausted immigrant" [5], who, after the time of arrival when he was a healthy person, able to work (effect "healthy migrant"), fell more ill due to harder work and insalubrious houses. Unhealthy living and working conditions could have a double effect: firstly, they increase the probability to become symptomatic from a condition of latent disease acquired in native countries; secondly, the transmission is easier from one symptomatic case to roommates and colleagues, if the houses and factories are overcrowded.

Other immigrants, where the aggregation is less common probably because they are more integrated with local population, this phenomenon does not occur, and incidence rates are the same or, in some cases, lower than those of native countries.

Anyway, TB incidence rates are always higher among immigrants than in the rest of Tuscany population (TB incidence rate was overall 6.93/100,000 during 2014 in Tuscany) [6].

The above rates were calculated in Tuscany considering just hospitalised cases, so that likely the number of real new cases could be even higher. Another limitation of our considerations is that hospitalisation rates were crude and not standardised: a more detailed work of standardisation, considering the annual number of cases stratified for age in each native country should be done, but these data are not yet available. A more complete and precise TB monitoring system not only in these countries, but also in Tuscany through the notification system, would consent more definitive conclusions.

However, the immigration trend in 2015 (more recent data on TB cases are not still available) showed that the same 12 nationalities were still the most represented. Foreigners living in Tuscany were 395,573 [3] and the percentages for the above nationalities are reported in Figure 1 [3]. Besides, during 2015, there was also the constant flow of refugees (153,600 arrivals by sea during 2015), almost coming from other TB endemic countries (26\% from Eritrea, $14 \%$ from Nigeria, $8 \%$ from Somalia, 6\% from Sudan and 5\% from Syria) [7].

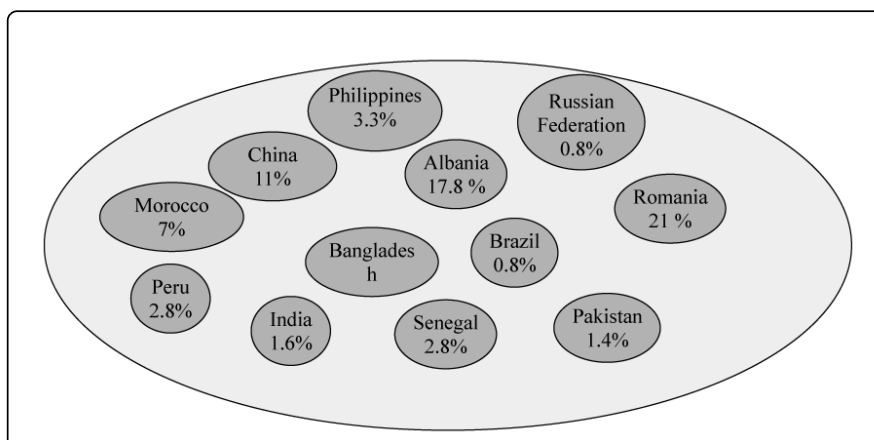

Figure 1: Percentages on the whole foreign population living in Tuscany for the 12 most represented nationalities.

\section{Conclusion}

Therefore, the enlargement of the BCG vaccination coverage for foreigner's on the whole regional area could be now an actual and urgent issue in order to prevent new cases of TB, whose incidence is always higher among immigrants. Children, who live near adults and often in close communities where the transmission of infection is much easier, even than the one in the original countries, are at higher risk of serious complications. Therefore, the protection of these children becomes now a relevant necessity that will be seriously evaluated.

\section{References}

1. Foreigners living in Prato at the 31st December of each year.

2. Bellini I, Nastasi A, Boccalini S (2016) Clinical and economic impact of a specific BCG vaccination program implemented in Prato, central Italy, involving foreign newborns on hospitalizations. Hum Vaccin Immunother 12: 2383-2390.

3. Foreigners living in Tuscany at the 1st January of each year stratified for nationality. 
Citation: Bellini I, Nastasi A, Boccalini S (2016) Further Considerations on the Need of a Specific BCG Vaccination Programme for Foreign Newborns. J Vaccines Vaccin 7: 348. doi:10.4172/2157-7560.1000348

Page 3 of 3

4. Annual TB incidence rate for each country.

5. G Costa, M Bassi, GF Gensini, M Marra, AL Nicelli, et al. (2014) L'equità nella salute in Italia. Secondo rapporto sulle disuguaglianze sociali in sanità. Franco Angeli pp: 121
6. Statistical data on infectious diseases, incidence rate for tubercolosis available online at? codice_asl $=9000 \&$ preselezione $=3$.

7. Godio G (2015) Rifugiati e migranti: i numeri della "non invasione". Italia. 